\title{
Organic brain damage and occupational solvent exposure
}

\author{
N M Cherry, F P Labrèche, J C McDonald
}

\begin{abstract}
Three hundred and nine men with organic dementia, cerebral atrophy, or psycho-organic syndrome admitted for five nights or more to one of 18 Quebec hospitals were individually matched with patients admitted (1) with some other psychiatric diagnosis and (2) to a general hospital. Lifetime occupational histories were obtained by telephone. Occupational exposure to solvents was assessed blind to type of case by (1) individual ratings and (2) a job exposure matrix; men who worked in moderate or high solvent concentrations for at least 10 years were considered exposed. With the psychiatric referent series, an odds ratio of 1.4 $(90 \% \mathrm{CI} 1 \cdot 0-2 \cdot 0)$ was calculated by individual exposure ratings and $1 \cdot 4(90 \% \mathrm{CI} 0 \cdot 9-2 \cdot 2)$ by job matrix. Increased risk was mainly in those with organic dementia or cerebral atrophy and an alcohol related diagnosis. The same pattern of risk was found against the general hospital referents. Adjustment for possible confounders did not alter the risk estimates appreciably. Also, lifetime job histories, compared in selected case-referent pairs, gave similar evidence of increased risk (odds ratio $2 \cdot 3 ; 90 \%$ CI $1 \cdot 0-5 \cdot 5)$. It is concluded that the combined effect of occupational solvent exposure and alcohol intake is probably an important cause of organic brain damage.
\end{abstract}

(British Journal of Industrial Medicine 1992;49:776-781)

During the past 15 years several epidemiological studies have provided evidence of an increased risk of neuropsychiatric illness in workers exposed over a long period to various solvents. ${ }^{1}$ In two studies ${ }^{23}$ cases were limited to dementia or Alzheimer's disease; in the remainder, case definition covered a wide range of psychiatric diagnoses. After reanalysis by Axelson in $1982^{4}$ of the case referent study with which he was previously associated, ${ }^{5}$ the highest risk was found in pensioners with senile or pre-senile

School of Occupational Health, McGill University, Montreal, Quebec, Canada

N M Cherry, F P Labrěche, J C McDonald dementia. This diagnostic group was also identified, although only after reclassification, in a Danish cohort. ${ }^{6}$ Other investigators have found the highest risk in neuroses ${ }^{78}$ psychoses, ${ }^{9}$ affective psychoses,${ }^{10}$ or non-psychotic conditions. ${ }^{11}$ Three reports have drawn attention to an increased risk of alcohol related neuropsychiatric disease in men exposed to solvents. ${ }^{12-14}$

The present investigation was designed to determine whether, in men with illness sufficiently disabling to require admission to hospital for at least five nights, exposure to solvents was more closely associated with organic psychoses or cerebral degeneration than with other psychiatric conditions. Previous studies of psychiatric patients, including our own, ${ }^{1}$ have not been sufficiently powerful to test this hypothesis.

\section{Methods}

DEFINITION OF CASE AND REFERENT SERIES

Cases and referents were identified from records of 18 psychiatric and general hospitals in urban communities of Quebec. The hospital records of men aged 40 to 69 years, admitted for at least five nights, April 1978 to March 1985, were examined and patients were noted whose first admission, when aged 40 years or more, had been within the past five years. Men whose final diagnosis, either primary or secondary, was one of the organic brain diseases included in ICD-9 codes 290.0,1,2,3,4,8,9; 291・1,2,9; $294 \cdot 0,1,8,9 ; 310 \cdot 1$; and $331 \cdot 0,1,2,9$, or parallel codes from the ICD-8 classification (see table 1 ) constituted the case series. Because of the large number of patients with a diagnosis of alcoholic dementia in certain hospitals, random samples were selected such that, in any one hospital, cases with alcoholic dementia did not exceed those with senile or presenile dementia.

The primary referent series comprised men with other psychiatric diagnoses. Patients with chronic alcoholism (ICD-9 code 303) or mental retardation (ICD-9 317-319) were excluded. Referents were matched individually to cases by hospital, on year of admission and age \pm 2 years; occasionally it was necessary to extend the match to \pm 3 years. To facilitate comparison with our parallel study ${ }^{1}$ a further referent series of patients admitted to the closest general hospital with any diagnosis other than psy- 
chiatric illness, chronic alcoholism, elective surgery, or accidental injury was matched to each case and also to each psychiatric referent on year of admission and age. Patients whose home address, telephone number or named contact was in Quebec or the adjacent provinces of Ontario or New Brunswick were eligible for inclusion but retained for study only if still resident there.

\section{INTERVIEW PROCEDURE}

A letter explaining the project was sent to the last known address and a telephone interview was attempted shortly afterwards. Interviewers, blind to case or referent state, asked the subject to list chronologically all employment since leaving school, and to help complete a checklist of occupational exposure to solvents, pesticides, or lead, together with information on other relevant factors such as alcohol intake, immigrant state, educational level, and head injury. Patients initially reluctant to collaborate were contacted again by telephone or mail some months later. If the patient had died or was, in the opinion of the family or hospital, incapable of completing the interview, a family member or friend was asked to provide the same information. A short form was sent by mail to any subject who persistently declined a telephone interview.

\section{EVALUATION OF EXPOSURE}

Solvent exposure was assessed in three ways, described in detail in our companion paper. ${ }^{1}$

Individual ratings were made by one of us (FL) for each job recorded. Intensity of exposure was estimated on a basic but extended 4 point scale: zero, (not more than the average citizen); 1, light exposure; 2, moderate exposure (about $30-50 \%$ of threshold limit value (TLV)); 3 , heavy exposure (over $50 \%$ of TLV).

Job matrix ratings were based on job category assessments made by three experts ("the London panel"). Each job recorded was allocated to a job category using the Canadian census four figure occupational code. These ratings used the same four point scale of exposure intensity.

Lifetime exposures were compared in 98 case and general hospital referent pairs in which either case or referent had been judged on individual ratings to have experienced a moderate or greater intensity for 10 years or more. The experts estimated which of the pair had been more heavily exposed and whether either exposure had been to a degree likely to be biologically important.

\section{CONFOUNDING FACTORS}

Information on seven potential confounders was collected by questionnaire as in the parallel study.' These included exposure to lead and pesticides, socioeconomic state, immigrant state, exposure to solvents outside work, school leaving age, head injury with loss of consciousness, and stroke ("or other disease of that kind"). A detailed history of alcohol intake was used to classify the subjects' drinking habits. A recorded intake of more than 42 units a week was considered to be excessive ( 1 unit equals $350 \mathrm{ml}$ of beer, $120 \mathrm{ml}$ of table wine, or $45 \mathrm{ml}$ of spirits). Incomplete questionnaires were assessed individually, blind to case state; intake was considered excessive where there was some suggestive comment, such as "drank like a fish". Immigrant state and exposure to solvents outside work, considered as confounders in the parallel study, ${ }^{1}$ did not differ between case and referent series in the study reported here.

\section{CHARACTERISTICS OF SAMPLE}

The final analysis was of 309 cases and a similar number in each of the two referent series. Long questionnaire interviews were obtained for $86 \%$ of cases, $82 \%$ of psychiatric referents, and $82 \%$ of general hospital referents, with limited information by short questionnaire for a further $8 \%, 10 \%$, and $10 \%$ respectively. Eleven cases, 11 psychiatric referents, and 11 general hospital referents were untraced; five cases, 14 psychiatric referents, and 12 general hospital referents refused to participate and two subjects (both cases) had died after leaving hospital and no proxy informant could be found. Some information on occupation was obtained from hospital records for 61 of the 66 subjects listed above for whom no other source was available.

Proxy interviews were much more frequent with cases; of 266 with long questionnaires, only $48(18 \%)$ were completed by the subject compared with 147 of $252(58 \%)$ for psychiatric referents and 127 of 254 $(50 \%)$ general hospital referents. Use of proxy respondents, all but nine being family members, was particularly high for cases of senile or presenile or multi-infarct dementia. In these groups only four of 97 long questionnaires were completed in full or in part by interview with the subject himself.

Table 1 shows the distribution by diagnostic group of cases and psychiatric referents. In 37 cases the diagnosis of organic brain damage was secondary, the primary diagnosis being of some other psychiatric disease. Table 2 shows the distribution of selected potential confounders for the 266 cases, 252 psychiatric, and 254 general hospital referents for whom long questionnaires were completed. Greater alcohol consumption was reported for cases than either referent series. Among the cases there were more reports of stroke and fewer of exposure to pesticides. The mean age of cases was $60 \cdot 8$ (range 40 to 69 ), psychiatric referents 60.5 (range 40 to 72 ), and general hospital referents $60 \cdot 7$ (range 40 to 71 ). 
Table 1 Case and referent diagnoses

\begin{tabular}{|c|c|c|c|c|}
\hline$I C D-9$ & $I C D-8$ & Diagnosis & Cases & $\begin{array}{l}\text { Psychiatric } \\
\text { referents }\end{array}$ \\
\hline $\begin{array}{l}290 \cdot 0-3,8,9 \\
290 \cdot 4 \\
291 \cdot 1,2,9 \\
293,295-299 \\
294 \cdot 0,1,8,9 \\
300-307 \\
308-9 \\
310 \cdot 1 \\
311 \\
312 \\
331 \cdot 0-9\end{array}$ & $\begin{array}{l}290 \cdot 0,1 \\
293 \cdot 0 \\
291 \cdot 1,2,9 \\
295-298 \\
293-4,299 \\
300-306 \\
307 \\
309 \cdot 6 \\
347 \cdot 1,794\end{array}$ & $\begin{array}{l}\text { Senile or presenile dementia } \\
\text { Arteriosclerotic dementia } \\
\text { Alcoholic dementia } \\
\text { Psychoses (non-organic) } \\
\text { Other organic psychoses } \\
\text { Neurotic and personality disorders } \\
\text { Acute reaction to stress and adjustment disorders } \\
\text { Organic psychosyndrome of non-psychotic severity } \\
\text { Depressive disorders } \\
\text { Disturbance of conduct } \\
\text { Cerebral degeneration }\end{array}$ & $\begin{array}{l}97(31 \%) \\
18(6 \%) \\
50(16 \%) \\
-\quad 28(9 \%) \\
- \\
55(18 \%) \\
- \\
61(20 \%)\end{array}$ & $\begin{array}{l}- \\
- \\
158(51 \%) \\
- \\
85(28 \%) \\
35(11 \%) \\
- \\
26(8 \%) \\
5(2 \%) \\
-\end{array}$ \\
\hline Total & & & $309(100 \%)$ & $309(100 \%)$ \\
\hline
\end{tabular}

Table 2 Distribution of potential confounders

\begin{tabular}{|c|c|c|c|}
\hline & Cases $(n=309)$ & Psychiatric referents ( $n=309$ ) & General hospital referents $(n=309$, \\
\hline $\begin{array}{l}\text { Long questionnaire completed } \\
\text { Head trauma } \\
\text { Stroke } \\
\text { Alcohol ever } \geqslant 14 \text { units week } \\
\text { Alcohol ever "excess" } \\
\text { Lead ever (at work) } \\
\text { Pesticides ever (at work) } \\
\text { School leaving } \leqslant 14 \text { years } \\
\text { Father's job "low status" }\end{array}$ & $\begin{array}{l}266 \\
17 \%(234) \\
15 \%(248) \\
41 \%(262) \\
21 \%(262) \\
9 \%(266) \\
3 \%(266) \\
52 \%(238) \\
31 \%(236)\end{array}$ & $\begin{array}{l}252 \\
13 \%(235) \\
5 \%(246) \\
30 \%(251) \\
15 \%(251) \\
8 \%(252) \\
9 \%(252) \\
44 \%(239) \\
35 \%(233)\end{array}$ & $\begin{array}{l}254 \\
10 \%(247) \\
10 \%(251) \\
28 \%(253) \\
8 \%(254) \\
8 \%(254) \\
9 \%(254) \\
46 \%(240) \\
32 \%(238)\end{array}$ \\
\hline
\end{tabular}

Number of questionnaires on which the information was recorded are shown in parentheses.

\section{STATISTICAL METHODS}

The data for cases and psychiatric referents were analysed in pairs to test the null hypothesis of no difference in level of exposure to solvents. It was decided, a priori, to test this hypothesis by comparing exposures to at least moderate solvent concentrations (level 2 or above) for 10 years or more before using firstly individual and then job title matrix exposure estimates. These analyses were then repeated using general hospital referents. Further analyses by conditional logistic regression were made to assess the contribution of confounding factors to any association found. One sided significance tests $(90 \%$ confidence intervals $(90 \% \mathrm{CIs}))$ were used throughout as the hypothesis was one of increased risk.

\section{Results}

Table 3 shows the odds ratios for exposure to solvents in the analysis of cases and psychiatric referents, using both individual ratings and job title matrix estimates, by diagnosis. The odds ratio overall was the same (1.4) by the two methods of exposure assessment. As the proportion of cases exposed was smaller $(8 \%)$ by the matrix method than by individual ratings $(15 \%)$, however, only the odds ratio for the individual ratings reached a $5 \%$ level of significance in a one tailed test. Within diagnostic group the risk was significantly increased for alcoholic dementia by both exposure estimates. The importance of variation between the estimates of risk for other diagnostic groups was difficult to assess because of small numbers.

As well as cases with a primary diagnosis of alcoholic dementia there were 25 with this or alcohol dependency as a secondary diagnosis. Cases were reclassified into four groups, firstly on whether or not an alcohol related diagnosis had been recorded and secondly on whether the primary or qualifying diagnosis had been one of organic psychosis, or cerebral degeneration, or one of non-psychotic severity (see table 4). With either method of exposure assessment the odds ratio was substantially increased for organic psychosis or cerebral degeneration when an alcohol related diagnosis was also present. Table 4 also shows a parallel analysis with general hospital referents. Again, the risk was highest when there was both an alcohol related diagnosis and one of organic psychosis or cerebral degeneration. This was less evident with individual than with matrix exposure ratings.

Only minor non-significant differences were found in reported alcohol consumption between exposed and non-exposed workers (table 5). Tables 6 and 7 show the extent to which alcohol interacted with solvent exposure. A matched analysis based on 214 
Table 3 Odds ratios for solvent exposure by diagnosis: psychiatric referents

\begin{tabular}{|c|c|c|c|c|c|}
\hline \multirow[b]{2}{*}{ Diagnosis } & \multicolumn{3}{|c|}{ Individual ratings* } & \multicolumn{2}{|c|}{ Job title matrix ${ }^{\star}$} \\
\hline & Pairs & Discordant & $O R(90 \%(C I)$ & Discordant & $O R(90 \%(C I)$ \\
\hline $\begin{array}{l}\text { Senile or pre-senile dementia } \\
\text { Cerebral degeneration } \\
\text { Arteriosclerotic dementia } \\
\text { Other non-alcoholic organic psychoses } \\
\text { Alcoholic dementia } \\
\text { Organic psychosyndrome of non-psychotic } \\
\text { severity }\end{array}$ & $\begin{array}{l}97 \\
61 \\
18 \\
28 \\
50 \\
55\end{array}$ & $\begin{array}{r:r}17 & 14 \\
12 & 8 \\
5 & 2 \\
7 & 6 \\
11 & 3 \\
7 & 8\end{array}$ & $\begin{array}{l}1 \cdot 2(0 \cdot 7-2 \cdot 2) \\
1.5(0 \cdot 7-3 \cdot 2) \\
2 \cdot 5(0 \cdot 6-9 \cdot 9) \\
1 \cdot 2(0 \cdot 5-2 \cdot 9) \\
3 \cdot 7(1 \cdot 3-10 \cdot 7) \\
0.9(0 \cdot 4-2 \cdot 1)\end{array}$ & $\begin{array}{l:l}9 & 6 \\
7 & 3 \\
0 & 2 \\
1 & 5 \\
8 & 2 \\
6 & 4\end{array}$ & $\begin{array}{l}1 \cdot 5(0 \cdot 6-3 \cdot 6) \\
2 \cdot 3(0 \cdot 7-7 \cdot 3) \\
0 \cdot 0(-) \\
0 \cdot 2(0 \cdot 0-1 \cdot 2) \\
4 \cdot 0(1 \cdot 1-14 \cdot 7) \\
1 \cdot 5(0 \cdot 5-4 \cdot 3)\end{array}$ \\
\hline Total & 309 & 5941 & $1.44(1.03-2.01)$ & 3122 & $1.41(0.89-2 \cdot 23)$ \\
\hline
\end{tabular}

*Data missing for 12 pairs, individual ratings; nine pairs, job title matrix ratings.

Table 4 Odds ratios for solvent exposure by main diagnostic group and alcohol related diagnosis

\begin{tabular}{|c|c|c|c|c|c|c|c|}
\hline \multirow[b]{2}{*}{ Diagnoses } & & \multirow[b]{2}{*}{$\begin{array}{l}\text { Alcohol } \\
\text { related }\end{array}$} & \multirow[b]{2}{*}{ Pairs } & \multicolumn{2}{|l|}{ Psychiatric referents } & \multicolumn{2}{|c|}{ General hospital referents } \\
\hline & & & & $\begin{array}{l}\text { Individual ratings } \\
O R(90 \%, C I)\end{array}$ & $\begin{array}{l}\text { Job title matrix } \\
O R(90 \%, 1)\end{array}$ & $\begin{array}{l}\text { Individual ratings } \\
O R(90 \%, C I)\end{array}$ & $\begin{array}{l}\text { Job title matrix } \\
\text { OR }(90 \%, C I)\end{array}$ \\
\hline \multirow{4}{*}{\multicolumn{2}{|c|}{$\begin{array}{l}\text { Organic psychoses } \\
\text { or cerebral degeneration } \\
\text { Organic syndrome } \\
\text { (non-psychotic) }\end{array}$}} & \multirow{7}{*}{$\begin{array}{l}+ \\
-\ldots \\
+ \\
+ \\
+\end{array}$} & 66 & $5 \cdot 3(1 \cdot 9-15 \cdot 0)$ & $5 \cdot 5(1 \cdot 6-19 \cdot 5)$ & $2 \cdot 0(0.9-4 \cdot 3)$ & $5.0(1.4-17 \cdot 9)$ \\
\hline & & & 188 & $1.2(0.8-1.8)$ & $0.9(0.5-1.6)$ & $0.9(0.6-1.4)$ & $1 \cdot 1(0.6-2 \cdot 0)$ \\
\hline & & & -9 & $0.3(0.0-1.6)$ & $1 \cdot 0(0 \cdot 1-10 \cdot 3)$ & - & $-\dagger$ \\
\hline & & & 46 & $1.5(0.5-4 \cdot 3)$ & $1.7(0 \cdot 5-5 \cdot 5)$ & $1.3(0.4-3.8)$ & $1.3(0.4-3.8)$ \\
\hline All & & & $\begin{array}{r}75 \\
234\end{array}$ & $2 \cdot 4(1 \cdot 2-5 \cdot 1)$ & $4.0(1.4-11.6)$ & $2 \cdot 0(0.9-4 \cdot 3)$ & $5 \cdot 5(1.6-19 \cdot 5)$ \\
\hline & $\because$ & & 234 & $1 \cdot 2(0.9-1 \cdot 8)$ & $1 \cdot 0(0 \cdot 6-1 \cdot 7)$ & $0 \cdot 9(0 \cdot 6-1 \cdot 4)$ & $1 \cdot 1(0 \cdot 6-1 \cdot 9)$ \\
\hline Total & & & 309 & $1 \cdot 4(1 \cdot 0-2 \cdot 0)$ & $1 \cdot 4(0 \cdot 9-2 \cdot 2)$ & $1 \cdot 1(0 \cdot 8-1 \cdot 6)$ & $1 \cdot 6(1 \cdot 0-2 \cdot 6)$ \\
\hline
\end{tabular}

*Data mising for 12 pairs, individual ratings; nine pairs, job title matrix ratings.

+ Did not converge: discordant pairs 10 .

Table 5 Alcohol consumption and solvent exposure: cases and psychiatric referents combined

\begin{tabular}{|c|c|c|c|c|}
\hline \multirow{3}{*}{$\begin{array}{l}\text { Maximum weekly } \\
\text { consumption of alcohol (units) }\end{array}$} & \multicolumn{4}{|c|}{ Solvent exposure } \\
\hline & \multicolumn{2}{|c|}{ Individual ratings } & \multicolumn{2}{|c|}{ Matrix ratings } \\
\hline & Not exposed & Exposed & Not exposed & Exposed \\
\hline $\begin{array}{l}\text { None } \\
\geqslant 1<14 \\
\geqslant 14<42 \\
\geqslant 42 \text { or "excess" } \\
\text { Total } \\
\text { No }\end{array}$ & $\begin{array}{l}41 \% \\
23 \% \\
19 \% \\
17 \% \\
100 \% \\
411\end{array}$ & $\begin{array}{l}40 \% \\
23 \% \\
19 \% \\
19 \% \\
100 \% \\
102\end{array}$ & $\begin{array}{l}42 \% \\
23 \% \\
18 \% \\
17 \% \\
100 \% \\
465\end{array}$ & $\begin{array}{l}29 \% \\
29 \% \\
21 \% \\
21 \% \\
100 \% \\
48\end{array}$ \\
\hline$\%^{2}$ & \multicolumn{2}{|c|}{$0 \cdot 12$} & \multicolumn{2}{|c|}{3.67} \\
\hline
\end{tabular}

pairs with information on alcohol consumption and stratified by drinking habits of the case (table 6) shows that the excess risk was largely confined to heavy drinkers. An unmatched analysis (table 7) confirms this and suggests that the combined effect was more than additive. Logistic regression analysis of matched pairs showed no significant interaction by either method of exposure assessment, consistent with a multiplicative relation.

The odds ratio for solvent exposure in pairs with complete information on six possible confounders other than alcohol was $1 \cdot 2(90 \% \mathrm{CI} 0 \cdot 8-2 \cdot 0)$ for individual ratings and $1 \cdot 1(90 \% \mathrm{CI} 0 \cdot 6-2 \cdot 1)$ for matrix ratings. These estimates were essentially unchanged by logistic regression analysis adjusting for these factors (table 8); however, the excess of stroke remained. An additional logistic regression, allowing for the effect of alcohol consumption and other confounders within 61 pairs in which the case had both an alcohol related diagnosis and one of organic dementia or cerebral degeneration, did not show any important or significant reduction in odds ratio.

Among the 28 pairs identified by two of the three experts as entailing important exposure were 18 pairs where the case only was exposed, eight where the 
Table 6 Solvent exposure and alcohol consumption (matched analysis): psychiatric referents

\begin{tabular}{lcll}
\hline $\begin{array}{l}\text { Alcohol consumption } \\
\text { (no of units/week } \\
\text { of case) }\end{array}$ & Pairs & $\begin{array}{l}\text { Individuals } \\
\text { ratings } \\
\text { OR }(90 \% C I)\end{array}$ & $\begin{array}{l}\text { Job title matrix } \\
\text { OR }(90 \% C I)\end{array}$ \\
\hline None & 74 & $1.6(0 \cdot 8-3 \cdot 1)$ & $1.0(0 \cdot 4-2 \cdot 6)$ \\
$\geqslant 1<14$ & 50 & $1 \cdot 1(0 \cdot 6-2 \cdot 2)$ & $0 \cdot 8(0 \cdot 3-2 \cdot 4)$ \\
$\geqslant 14<42$ & 47 & $1.0(0 \cdot 5-2 \cdot 2)$ & $1 \cdot 0(0 \cdot 3-3 \cdot 2)$ \\
$\geqslant 42$ or excess & 43 & $3.0(1 \cdot 0-9 \cdot 0)$ & $3.0(0 \cdot 8-11 \cdot 5)$ \\
Total & 214 & $1 \cdot 4(0 \cdot 9-2 \cdot 0)$ & $1 \cdot 2(0 \cdot 7-2 \cdot 0)$ \\
\hline
\end{tabular}

Table 7 Odds ratios by solvent exposure and alcohol consumption (unmatched analysis): psychiatric referents

\begin{tabular}{llll}
\hline $\begin{array}{l}\text { Alcohol } \\
\text { consumption }\end{array}$ & $\begin{array}{l}\text { Solvent } \\
\text { exposure }\end{array}$ & $\begin{array}{l}\text { Individual ratings } \\
\text { OR }(90 \% C I)\end{array}$ & $\begin{array}{l}\text { Job title matrix } \\
\text { OR }(90 \% \text { CI) }\end{array}$ \\
\hline No excess & - & 1.0 & 1.0 \\
Excess & + & $1.3(0 \cdot 8-2 \cdot 0)$ & $1 \cdot 1(0 \cdot 6-1 \cdot 9)$ \\
& - & $1.6(1 \cdot 0-2 \cdot 5)$ & $1.5(1 \cdot 0-2 \cdot 3)$ \\
& + & $2 \cdot 4(0.9-6 \cdot 2)$ & $4 \cdot 2(1 \cdot 0-14 \cdot 1)$ \\
\hline
\end{tabular}

Table 8 Solvent exposure and confounding factors other than alcohol. Logistic regression analysis (139 pairs): psychiatric referents

\begin{tabular}{lll}
\hline & Exposure & \\
\cline { 2 - 3 } & $\begin{array}{l}\text { Individual ratings } \\
\text { OR }(90 \% C I)\end{array}$ & $\begin{array}{l}\text { Job title matrix } \\
\text { OR }(90 \% \mathrm{CI})\end{array}$ \\
\hline Head trauma & $1 \cdot 7(0 \cdot 9-3 \cdot 0)$ & $1 \cdot 7(0 \cdot 9-3 \cdot 0)$ \\
Stroke & $2 \cdot 4(1 \cdot 1-4 \cdot 9)$ & $2 \cdot 4(1 \cdot 2-4 \cdot 8)$ \\
Lead exposure & $1 \cdot 5(0 \cdot 6-3 \cdot 6)$ & $1 \cdot 5(0 \cdot 7-3 \cdot 7)$ \\
Pesticide exposure & $0 \cdot 4(0 \cdot 2-0 \cdot 9)$ & $0 \cdot 4(0 \cdot 2-0 \cdot 9)$ \\
School leaving & $1 \cdot 1(0 \cdot 8-1 \cdot 7)$ & $1 \cdot 1(0 \cdot 8-1 \cdot 7)$ \\
Father's job status & $1 \cdot 1(0 \cdot 7-1 \cdot 7)$ & $1 \cdot 1(0 \cdot 7-1 \cdot 7)$ \\
Exposure to solvents & $1 \cdot 2(0 \cdot 8-2 \cdot 1)$ & $1 \cdot 1(0 \cdot 5-2 \cdot 2)$ \\
\hline
\end{tabular}

referent only was exposed, and one pair in which both were exposed. This gave an odds ratio of $2 \cdot 3(90 \% \mathrm{CI}$ $1 \cdot 0-5 \cdot 5)$. In the 21 pairs where all three experts agreed that the exposure was important, the corresponding figures were 16 case only and five referent only, giving an odds ratio of $3 \cdot 2(90 \%$ CI $1 \cdot 2-10 \cdot 3)$. In this analysis the referents were from general hospital admissions.

\section{Discussion}

The hypothesis under test was that occupational exposure to solvents was more frequent in patients admitted to hospital with organic brain damage than with other psychiatric diagnoses. This was significantly so by all three methods of assessment of exposure, although the increased risk was only about $40 \%$ by individual and matrix values. More interesting, however, was the finding that the excess was concentrated among heavy drinkers, judged either by associated diagnoses of alcoholism (OR $>5.0)$ or by recorded alcohol consumption $(\mathrm{OR}=3 \cdot 0)$. In patients with less serious non-psychotic disease, the odds ratio was about 1.5 in the absence of an alcohol related diagnosis. This group of cases, included to facilitate comparison with previous studies of mild neuropsychiatric disease, was too small for detailed analysis, but the risk found was compatible with these earlier reports.

The similarity in drinking habits of solvent exposed and non-exposed subjects suggests that the overall difference in risk was not due to the confounding effect of intake of alcohol. Instead, it implies the existence of a direct or indirect interaction between the effects of these two toxic agents. The most straightforward explanation is that a greater load of circulating neurotoxic materials-ingested alcohol and inhaled solvent-increases the risk of brain damage, particularly as the entry of one may delay the elimination of the other. ${ }^{15}$ Alternatively, the established effects of one may interfere with the subsequent ability of the body to deal satisfactorily with the other. For example, cirrhosis from whatever cause would be expected to impair solvent or alcohol detoxification. Equally, persons with solvent induced brain damage may tolerate alcohol less well and so be more likely to manifest its effects. It is also possible, of course, that cases of dementia resulting wholly or in part from solvent exposure might, in persons with high consumption of alcohol, be given an alcoholrelated diagnosis.

The present study has strengths and weaknesses. Cases and psychiatric referents were closely matched in age and pairs drawn from the same hospital at the same time, differing only in diagnosis by the same group of psychiatrists. Occupational histories were taken and estimates of exposure to solvents made in ignorance of case or referent state. Less satisfactory was the greater frequency of proxy interviews with cases than referents. The direction or degree of any resulting bias is difficult to assess but, in 82 pairs in whom both case and referent were interviewed by proxy, the odds ratio was 1.5 , slightly higher than for the whole sample. This problem did not arise in our parallel study ${ }^{1}$ where few of the cases were demented.

The present study is limited by the fact that the cases were drawn from patients admitted to hospital; such admissions depend in part on social and other circumstances. Also, inclusion of only a sample of cases with alcoholic dementia and exclusion of alcoholics from the referent series, makes it difficult to refer our findings to the general population. In the first two hospitals visited alcoholic dementia constituted half the eligible cases. Thus, without sampling, the overall risk would have been appreciably greater than the odds ratio of 1.4 reported here.

The positive result of the present study contrasts with the negative findings of our parallel investigation. ${ }^{1}$ In the latter no excess risk was found in 
psychiatric admissions overall compared with general hospital admissions. In so far as a modest non-significant increase in risk was seen after very heavy exposure, this was confined to cases with nonpsychotic diagnoses-as in some previous reports. ${ }^{7811}$ Exposure to solvents may thus be related to two kinds of mental disorder, affective illness (only weakly supported by our parallel study) and disabling organic psychosis or cerebral degeneration, with alcohol consumption a major factor.

This study was supported by the Institut de recherche en santé et en sécurité du travail du Québec. $\mathrm{O}$ Axelson, R Riala and $\mathrm{H}$ A Waldron participated in the expert panel review of job histories and related exposures. Cases and referents were identified from hospital records by Madeleine Ferron; questionnaires were administered by Donna Amyot.

Requests for reprints to: Professor N M Cherry, Centre for Occupational Health, University of Manchester, Stopford Building, Oxford Road, Manchester M13 9PT.

1 Labrèche FP, Cherry NM, McDonald JC. Psychiatric disorders and occupational solvent exposure. $\mathrm{Br} J$ Ind Med 1992;49: 820-6.

2 O'Flynn RR, Monkman SM, Waldron HA. Organic solvents and pre-senile dementia: a case referent study using death certificates. Br J Ind Med 1987;44:259-62.

3 Shalat SL, Seltzer B, Baker EL. Occupational risk factors and Alzheimer's disease; a case-control study. J Occup Med 1988;30:934-6.

4 Axelson O. Epidemiology of solvent-related neuropsychiatric disorders. In: Cherry NM, Waldron HA, eds. The neuropsichological effects of solient exposure. Havant: The Colt Foundation, 1983:85-99.

5 Axelson $O$, Hane $M$, Hogstedt C. A case-referent study on neuropsychiatric disorders among workers exposed to solvents. Scand J Work Enitiron Health 1976;2:1+20.

6 Mikkelsen S. A cohort study of disability pension and death among painters with special regard to disabling pre-senile dementia as an occupational disease. Scand $J$ Soc lled 1980; (suppl 16):34-43.

7 Lindstrom K, Riihimaki H, Hanninen K. Occupational solient exposure and neuropsychiatric disorders. Siand J IFirk Environ Health 1984;10:321-3.

8 van Vliet C, Swaen GMH, Volovics A, al Neuropsvchiatric disorders among solvent exposed workers. First results from a Dutch case control study. Int Arch Occup Enciron Hialth 1990;62:127-32.

9 Rasmussen H, Olsen J, Lauritsen J. Risk of encephalopathia among retired solvent-exposed workers. J Oicup lid 1985;27:561-6.

10 Brackbill RM, Maizlish N, Fischbach T. Risk of neuropsychiatric disability among painters in the United States. Scand $J$ Work, Entiron Health 1990;16:182-8.

11 Olsen J, Sabroe S. A case-reference study of neuropsychiatric disorders among workers exposed to solvents in the Danish wood and furniture industry. Scand J Soc lled 1980; suppl 16):44-9.

12 Cherry NM, Labrèche F, McDonald JC. Dementia and solvent exposure at work. In: Hogstedt C, Reuterwall C, eds. Progress in occupational epidemiology. Excerpta.Medica, International congress series 1988;809:247-8

13 Guberan E, Usel M, Raymond L, Tissot R, Sweetnam PM. Disability, mortality, and incidence of cancer among Geneva painters and electricians: a historical prospective study. $\mathrm{Br} J$ Ind Med 1989;46:16-23.

14 Lundberg I, Gustavsson A, Nise G. Neuropsychiatric illness among painters-interaction between solvents and alcohol. Abstract, 23rd international congress on occupational health, Montreal, Canada, September 1990.

15 Wilson HK, Robertson SM, Waldron HA, Gompertz D. The effect of alcohol on the kinetics of mandelic acid excretion in volunteers exposed to styrene. Br J Ind Med 1983;40:75-80.

Accepted 9 March 1992 